\title{
Glutamate: A Safe Nutrient, Not Just a Simple Additive
}

\author{
Cécile Loï ${ }^{\mathrm{a}}$ Luc Cynober ${ }^{\mathrm{b}, \mathrm{c}}$

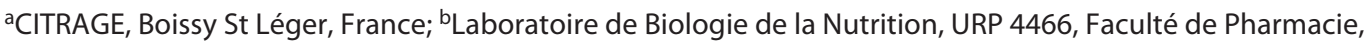 \\ Université de Paris, Paris, France; 'Service de Biochimie, Hôpital Cochin, AP-HP, Paris, France
}

\author{
Keywords \\ Glutamate $\cdot$ Pharmacokinetics - Safety $\cdot$ Metabolism . \\ Nutrient · European Food Safety Authority
}

\begin{abstract}
Background: In 2017, a European Food Safety Authority (EFSA) opinion on the use of glutamate and its salts as food additives led to an Acceptable Daily Intake (ADI) of $30 \mathrm{mg} / \mathrm{kg}$ body weight/day. Then, in 2021, an EFSA statement presented a proposal for harmonizing the establishment of HealthBased Guidance Values for nutrients that are also regulated substances (including food additives). The present review argues that the 2017 glutamate ADI is unsuitable because safety of glutamate should firstly consider its status as a nutrient and not only as an additive. Summary: Glutamate is a non-essential amino acid playing a key role in nitrogen homeostasis. The dietary exposure to glutamate in adults is extensive, due to its ubiquitous presence in foods, under three forms: bound to proteins, naturally free and free form added as an additive. Glutamate naturally included in proteins is the major source of dietary glutamate. Thus, since it plays a role in nitrogen homeostasis, it is a nutrient before being an additive. Its pharmacokinetics are largely impacted by concomitant food intake, but the extent to which plasma glutamate concentration must rise to have deleterious effects is never encountered in humans consuming glutamate in their daily diets. This is due to the fact that glutamate is highly
\end{abstract}

Karger@karger.com www.karger.com/anm

Karger"
(C) 2022 The Author(s)

Published by S. Karger AG, Basel

This is an Open Access article licensed under the Creative Common Attribution-NonCommercial-4.0 International License (CC BY-NC) (http://www.karger.com/Services/OpenAccessLicense), applicable to the online version of the article only. Usage and distribution for commercial purposes requires written permission. metabolized in the splanchnic area. Key Message: Glutamate should be considered as a safe nutrient before being considered as an additive by risk assessor.

(c) 2022 The Author(s).

Published by S. Karger AG, Basel

\section{Introduction}

First of all, what are we talking about? Glutamate, or glutamic acid, added to a diet is generally in the form of monosodium glutamate (MSG), or one of its sodium, potassium, calcium, ammonium, and magnesium salts (additives designated E620-625). But glutamate is also naturally present in food, either in free form or bound to proteins. However, as MSG and all other glutamate salts dissociate in aqueous solution and so behave exactly as free glutamate [1], the latter term will be used. And when we consider "glutamate in any form," we use the term of glutamates.

In 1987, the Joint FAO/WHO Expert Committee on Food Additives evaluated glutamic acid and its sodium, potassium, calcium, ammonium, and magnesium salts [2]. It was established that glutamate should not have a numerical Acceptable Daily Intake (ADI): it is a "not specified" ADI molecule. Indeed, it was considered that substances of low toxicity such as glutamates should be labelled with an ADI "not specified." According to the opinion of the Committee, on the basis of the available 
data (chemical, biochemical, toxicological, and other), the total dietary intake of glutamates arising from their use at the level necessary to achieve the desired technological effect and from their acceptable background in food does not represent a hazard to health. For that reason, the Committee considered that the establishment of an ADI expressed in numerical form was not deemed necessary for glutamates. In the same way, in 1990, the Scientific Committee for Food of the European Community also allocated an ADI "not specified" for MSG [3]. In 2017, an European Food Safety Authority (EFSA) opinion on the use of glutamate and its salts as food additives led to an ADI of $30 \mathrm{mg} / \mathrm{kg}$ body weight (bw)/day based on a toxicological endpoint of neurodevelopmental toxicity in rats [4]. The EFSA panel noted that this ADI is below usual mean and high level of total intake of glutamates in food and drinks in humans. In 2018, all relevant and available aspects of glutamates (i.e., glutamate in any form) metabolism and safety in human nutrition were discussed by a panel of experts, and their conclusions did not warrant a change in the previous ADI "not specified" of glutamate and its salts [5].

In 2021, an EFSA Statement presents a proposal for harmonizing the establishment of Health-Based Guidance Values for regulated substances that are also nutrients [6]. It recommended that nutrient safety should take into consideration the risk of adverse effects observed at high dietary doses for the consumer and associated with the total dietary intake of the nutrient and under regulated use. This differs from what was considered in 2017 to establish the glutamate ADI: indeed, non-food additive intake was ignored. In addition, for the pivotal safety study, unusual glutamate intake, i.e., bolus dose of $3 \mathrm{~g}$ of glutamate without food, was taken into consideration, instead of the usual consumption of glutamate in food and drinks.

The aim of the present paper was to review current knowledge on:

1. The contribution of different dietary sources of glutamate to the total consumption of this nutrient.

2. The impact of glutamate form (free or protein-bound) and concomitant food intake on its pharmacokinetics.

3. Glutamate safety.

\section{Glutamate Metabolism and Functions in the Organism}

For the average person, glutamate is associated with the umami taste and it is used in savoury food such as seasonings, condiments, meat products, soups, broths, etc., to enhance their flavour and palatability [7]. More importantly, glutamate is a non-essential amino acid (AA) highly involved in nitrogen and energy metabolism. It plays a key role in nitrogen homeostasis [8]. Dietary glutamate is absorbed from the intestinal lumen (in a dose-dependent and saturable process) and is highly catabolized ( 90\%) in the splanchnic area [9-11]. Indeed, glutamate is the most important fuel for the gut [12]. In the enterocyte, glutamate is transaminated into various AAs, mainly into alanine but also into proline, aspartate, and citrulline [8]. As a result, very little glutamate appears in the systemic blood after a meal.

In the liver, glutamate metabolism is compartmentalized. In periportal liver cells (the major cell population), glutamine metabolism provides ammonia for ureagenesis and glutamate for gluconeogenesis [13]. In healthy conditions, this periportal metabolism is favoured. In perivenous hepatocytes (a small population representing $7 \%$ of all hepatocytes of an acinus) [14], there is glutamine synthetase allowing glutamine synthesis from glutamate [15]. This glutamine is released by the liver and taken up by kidneys where it is deaminated to release ammonium which is excreted in the urine. In acidosis conditions, this perivenous metabolism is favoured versus periportal use. Thus, this tight metabolic organization allows to remove ammonia in response to any of the situations [14].

In rats, it has been shown that a large part of glutamate appearing in the systemic circulation following diet supplementation (a 15\% casein diet supplemented with $7.2 \%$ glutamate) is found in muscle [16], where it leads to alanine and glutamine synthesis. In the same way, the adipose tissue takes up glutamate to release glutamine [17].

Concerning glutamate metabolism in the brain, in the late 1960s, it was thought that consumption of glutamate, mainly in the form of food additive, induced increased brain glutamate levels, causing functional disruptions. However, these results were obtained using non-physiological conditions, including bolus parenteral injections of high glutamate dosages (see below for details) in rodents. Now, it is well documented that in humans, in a context of normal diets, glutamate is highly metabolized in the splanchnic area and the extent to which plasma glutamate concentration must rise to produce effects in brain, such as it was observed in rodents, is never encountered [8]. This is especially true since the perceived pleasantness of ingested glutamate diminishes markedly as its concentration rises over the optimal level, inducing that food-added glutamate intake in the human diet is selflimiting [18]. 
Table 1. Intakes of glutamates in food and drinks (from Tennant [31] with authorization)

\begin{tabular}{|c|c|c|c|c|c|c|c|}
\hline Glutamate form & $\begin{array}{l}\text { Mean/ } \\
\text { high level }\end{array}$ & $\begin{array}{l}\text { Infants } \\
\text { (12 weeks to } 11 \text { months) }\end{array}$ & $\begin{array}{l}\text { Toddlers } \\
\text { (12-35 months) }\end{array}$ & $\begin{array}{l}\text { Children } \\
\text { (3-9 years) }\end{array}$ & $\begin{array}{l}\text { Adolescent } \\
\text { (10-17 years) }\end{array}$ & $\begin{array}{l}\text { Adults } \\
\text { (18-64 years) }\end{array}$ & $\begin{array}{l}\text { Elderly } \\
\text { ( } \geq 65 \text { years) }\end{array}$ \\
\hline \multirow[t]{2}{*}{ Natural protein-bound } & Mean & $82-186$ & $211-307$ & $124-259$ & $72-145$ & $70-107$ & $68-111$ \\
\hline & High level & $121-361$ & $286-444$ & $173-326$ & 104-192 & $95-145$ & $71-138$ \\
\hline \multirow[t]{2}{*}{ Natural free } & Mean & $10-22$ & $15-37$ & $12-31$ & $8-17$ & $7-15$ & $5-17$ \\
\hline & High level & $21-77$ & $20-54$ & $18-82$ & $12-38$ & $11-36$ & $11-27$ \\
\hline \multirow[t]{2}{*}{ Natural total glutamate } & Mean & $92-198$ & $232-331$ & $136-289$ & $81-158$ & $81-118$ & $76-123$ \\
\hline & High level & $132-381$ & $310-468$ & $193-358$ & $113-206$ & $106-155$ & $76-126$ \\
\hline \multirow[t]{2}{*}{ Additive } & Mean & $6-12$ & $6-37$ & $7-31$ & $4-10$ & $2-13$ & $2-15$ \\
\hline & High level & $18-59$ & $20-82$ & $17-76$ & $11-45$ & $7-35$ & $4-34$ \\
\hline \multirow[t]{2}{*}{ Total } & Mean & $98-211$ & $244-346$ & $167-319$ & $92-170$ & $88-126$ & $88-125$ \\
\hline & High level & $137-388$ & $337-474$ & $241-408$ & $130-224$ & $118-176$ & $88-167$ \\
\hline
\end{tabular}

Data are expressed in milligrams glutamic acid/kilogram bw/day.

Inter-Organ Exchanges of Glutamate. Unlike those of glutamine, glutamate inter-organ exchanges are quantitatively and qualitatively low, being limited to a flux from liver to muscle in a wide range of situations: post-absorptive state $[19,20]$, starvation of overweight subjects [19] and in sepsis [21], and its metabolism is partitioned within organs [22-24]. It is one of the AAs which are present at the highest levels in its free form in liver, kidney, and muscle $(2-5 \mathrm{mmol} / \mathrm{L})$. Its concentration in plasma is relatively low $(50 \mu \mathrm{mol} / \mathrm{L})$ [25] and stable [26], as its turnover is low $[27,28]$.

\section{Evidence that Glutamate Naturally Present in Food Is the Major Source of Glutamate Intake}

The dietary exposure to glutamate in adults is extensive, due to its ubiquitous presence in foods. Three sources of glutamate are encountered in food:

- The first source, naturally bound to proteins, is the most important. Indeed, glutamate is amongst the most abundant AAs (8-10\%) found in dietary proteins and as such naturally occurs in foods with high protein content (meats, seafood, stews, soups, and sauces) [29]: $100 \mathrm{~g}$ of protein supply 4-12 g of glutamate on average [1]. Gliadin and $\alpha$-casein are the richest plant and animal proteins in glutamate (45.7 and $16.5 \mathrm{~g}$ of glutamate/100 g of protein respectively) [30]. Levels of glutamate from protein in animal products are generally around $25 \mathrm{~g} / \mathrm{kg}$ of food [31].

Glutamate: A Safe Nutrient, Not Just a

Simple Additive
- The second source, naturally free form of glutamate, occurs in fermented foods and in many foods consumed by humans: seaweeds, cheeses, fermented beans, tomatoes, mushrooms, cured hams, scallops, tuna, green peas, fish and soy sauces, beef, yeast extract, hydrolyzed vegetable proteins and autolysed yeast extract, human, and cow's milk [12]. Free glutamates can occur at relatively high concentrations (18 $\mathrm{g} / \mathrm{kg}$ of food) in certain fermented foods such as cheese, preserved meats, and soy sauce, depending on ageing and maturation [31].

- The third source is free form added to the diet as an MSG additive (see above for details). The most prominent flavour enhancing capacity and umami potency is used to enhance the flavour and palatability of foods [7]. Food additive levels for glutamates in the European Union are limited to $10 \mathrm{~g} / \mathrm{kg}$ of food in 65 broad categories of foodstuffs by the provisions of Regulation (EC) No. 1333/2008 and Commission Regulation (EU) No. 1129/2011. In seasoning, condiments, and salt substitutes, glutamates are authorised at quantum satis (QS) [4]. However, from a practical viewpoint, glutamates would only be used in savoury foods to modulate the umami taste and so would be used in only a small proportion of the foods for which they are authorised [31].

In 2018, Tennant [31] has nicely evaluated potential intakes from all glutamate sources and the relative contribution from each source separately among the European population. The author observed that natural protein-bound glutamate was mainly provided by cow's milk

Ann Nutr Metab 2022;78:133-146 
for children and meat and some cereal products for adults [31]. Ripened cheese, preserved meats, potatoes, and tomatoes contributed most to average intakes of dietary natural free glutamate. Regarding free glutamate from addition of E620-625, it was mainly provided by pastries, cakes, and soups. Data are summarized in Table 1.

The author reported some uncertainties which could lead to underestimated intakes of free glutamate from natural sources and to overestimate exposure to the other forms of glutamate (i.e., naturally protein-bound and additive) (see Tennant [31] for more details). However, Tennant's [31] evaluations of free glutamate are close to previous estimates in the EFSA Opinion [4] and that of total glutamates are close to previous estimates in published literature [32-36].

Results of this work show that average population intakes of additive free and natural free glutamate ranged from $2 \mathrm{mg} / \mathrm{kg}$ bw/day (adults and elderly) to $37 \mathrm{mg} / \mathrm{kg}$ bw/day (toddlers) and $5 \mathrm{mg} / \mathrm{kg}$ bw/day (elderly) to $37 \mathrm{mg} /$ $\mathrm{kg}$ bw/day (toddlers), respectively. Thus, the use of glutamate as food additives results in free glutamate intakes comparable to those from natural sources. On the other hand, average population intakes of total dietary glutamates ranged from $88 \mathrm{mg} / \mathrm{kg}$ bw/day (elderly) to $346 \mathrm{mg} /$ $\mathrm{kg}$ bw/day (toddlers). High-level intakes were $474 \mathrm{mg} / \mathrm{kg}$ bw/day for toddlers. Thus, average additive glutamate consumption represents between 6 and $12 \%$ of total glutamate intake as already demonstrated by others $[1,37$, 38 ] and up to $20 \%$ for high-level consumption, it contributes only a small proportion of total intake of glutamates from all sources. It can also be noted that in East and Southeast Asian countries, free glutamate intakes as additive are 2-3 times higher when compared to those reported in the USA and Europe [39, 40], without consequences in terms of safety as detailed below.

\section{Are Glutamate Pharmacokinetics Dependent on Its Form (Free or Protein-Bound) and Concomitant Food Intake?}

After ingestion, proteins are digested releasing free glutamate and di- and tri-peptides. All are taken up by enterocytes, and peptides are further metabolized into free glutamate into enterocytes. Hence, glutamates appear as free glutamate in portal circulation whatever its form of ingestion. It is important to have in mind that, as mentioned above, $90 \%$ of dietary glutamate is catabolized into the splanchnic area [9-11] and a very low glutamate amount appears in the systemic blood after a meal. This has been well demonstrated by Tsai and Huang [41] who studied circadian variations in plasma glutamate in 10 healthy men receiving ordinary Taiwanese meals. The design was as follows: the subjects ingested a standardized diet comprising 3 meals and 2 snacks. The well-balanced meals provided $40 \mathrm{kcal} / \mathrm{kg} / \mathrm{day}$, with $15 \%$ of the energy as protein $(1.5 \mathrm{~g} / \mathrm{kg} /$ day, $50 \% / 50 \%$ of animal/vegetable proteins), $55 \%$ as carbohydrate, and $30 \%$ as fat. During the test day, blood was sampled throughout the 24 -h period for AA analysis. Results showed that the plasma concentrations of large neutral AAs reached high peaks at about 9:00-11:00 p.m. This result was also observed by others [42]. Such peaks were not found for plasma glutamate, whereas circadian variations in plasma glutamate as a function of the time of day were statistically significant, with a moderate but significant postprandial plasma glutamate increase after lunch and dinner [41]. Thus, the fact that plasma glutamate did not exhibit the peaks reached by other AAs supports the idea that the organism does all it can to limit glutamate bioavailability in order to avoid neurotoxic excess. Actually, glutamate required for protein synthesis is generated intracellularly from protein degradation, transamination reactions and, in some cell types, glutamine deamination.

Glutamate Pharmacokinetics following MSG Ingestion Pharmacokinetic studies have been summarized recently by Cynober [8]. Rutten et al. [43] administered 30 $\mathrm{mg}$ of glutamate $/ \mathrm{kg}$ bw orally every $20 \mathrm{~min}$ for $220 \mathrm{~min}$. The plasma glutamate level peaked at $80 \mathrm{~min}$ ( 5 times the basal value, $601 \pm 68 \mu \mathrm{mol} / \mathrm{L}$ ) and remained steady despite further administration every $20 \mathrm{~min}$, assuming a saturable mechanism for intestinal absorption and clearance by the intestine.

Stegink et al. [44] provided a beef consommé (supplying $10 \mathrm{kcal} / 240 \mathrm{~mL}$ reconstituted broth and $1 \mathrm{mg} / \mathrm{kg}$ bw of glutamate), alone or with 25 or $50 \mathrm{mg}$ MSG/kg bw to 9 healthy subjects. Plasma glutamate rose dose-dependently reaching a peak at $30 \mathrm{~min}$ but with no significant increase $(54 \pm 12 \mu \mathrm{mol} / \mathrm{L})$ when consommé is given alone. Plasma glutamate increase was 2.5 -fold over baseline (102 $\pm 21 \mu \mathrm{mol} / \mathrm{L}$ ) when $25 \mathrm{mg} \mathrm{MSG} / \mathrm{kg}$ bw were added and 4.5 -fold over baseline $(170 \pm 80 \mu \mathrm{mol} / \mathrm{L})$ when $50 \mathrm{mg}$ MSG/kg bw were added.

When $150 \mathrm{mg}$ MSG/kg bw was administered alone and in bolus to 6 or 8 healthy adult subjects in the post-absorptive state, plasma glutamate peaked up to 19 times the basal value $(594 \pm 465 \mu \mathrm{mol} / \mathrm{L})$ at $45 \mathrm{~min}$ and returned to basal levels at 180 min post-ingestion [45]. In the same way, Fernstrom et al. [46] administered $160 \mathrm{mg}$ of MSG/ 
$\mathrm{kg}$ bw in 8 healthy adult subjects in the post-absorptive state and observed that plasma glutamate peaked (11 times the basal value $[530 \mu \mathrm{mol} / \mathrm{L}])$ at $60 \mathrm{~min}$ and returned to basal levels at $180 \mathrm{~min}$ post-ingestion. This was also confirmed by Graham et al. [22] some years later, who administered $150 \mathrm{mg}$ of MSG/kg bw orally to 9 healthy young adults and showed that plasma glutamate peaked ( 8 times the basal value $[437 \mu \mathrm{mol} / \mathrm{L}]$ ) either 30 or $45 \mathrm{~min}$ after ingestion and declined rapidly: at $90 \mathrm{~min}$, glutamate was no longer significantly elevated over the basal level.

Thus, it can be concluded that when administered alone, MSG leads to rapid increase in plasma glutamate, with a maximum peak around $600-700 \mu \mathrm{mol} / \mathrm{L} 30-60$ min after ingestion, and then to a rapid decrease reaching basal value within $90-180 \mathrm{~min}$. It is important to note that the conditions of these studies are very far from real-life conditions as no person consumes only isolated MSG.

\section{Impact of Carbohydrates on Glutamate}

\section{Pharmacokinetics following MSG Ingestion}

When MSG (150 mg/kg bw) was given together with carbohydrate $(1.1 \mathrm{~g} / \mathrm{kg}$ bw in the form of hydrolysed corn starch), plasma glutamate peaked at $60 \mathrm{~min}$ and returned to basal levels at $180 \mathrm{~min}$ post-ingestion, but its increase was eight times less important than when MSG was ingested alone $(71 \pm 36 \mu \mathrm{mol} / \mathrm{L}$ compared to $594 \pm 465$ $\mu \mathrm{mol} / \mathrm{L}[45])$. The authors suggest that carbohydrate increases the flux of pyruvate in enterocytes, facilitating the transamination of glutamate into alanine. This explains the release of alanine instead of glutamate in the portal vein, and thus the lower increase of plasma glutamate after MSG plus carbohydrate ingestion. This was confirmed 3 years later by the same team who gave to 6 healthy adults (mean weight $73.4 \mathrm{~kg}$ ) a beef consommé (the same as in a previous study [44]), $50 \mathrm{mg}$ MSG/kg bw and sucrose (5 $\mathrm{g} / \mathrm{kg} \mathrm{bw})$. Appearance of glutamate was strongly blunted with sucrose (about 3 times less: $55 \pm 22 \mu \mathrm{mol} / \mathrm{L}$ compared to $181 \pm 70 \mu \mathrm{mol} / \mathrm{L}$ ), and there was marked rise in alanine ( $+50 \%$ vs. basal), which was not observed in the absence of sucrose [47]. Again, it is important to note that the conditions of this study are far from real-life conditions as no person consumes only isolate MSG added with only carbohydrates.

\section{Glutamate Pharmacokinetics following Meals}

In the Tsai and Huang [41] study presented above, the moderate but significant postprandial plasma glutamate increase after lunch and dinner reached about $47.6 \pm 14.2$ $\mu \mathrm{mol} / \mathrm{L}$ (1.4-fold over baseline) with a maximum gluta- mate concentration about $60 \mathrm{~min}$ after lunch or dinner. Amount of glutamate contained in these meals was not specified. Stegink et al. [48] observed a plasma glutamate increase of the same order of magnitude after ingestion by healthy adults of a ready-to-feed liquid meal (Sustagen ${ }^{\circledR}$, bringing $0.4 \mathrm{~g}$ of proteins $/ \mathrm{kg}, 1.12 \mathrm{~g}$ of carbohydrates $/ \mathrm{kg}, 0.06 \mathrm{~g}$ of fats $/ \mathrm{kg}$ and $55 \mathrm{mg}$ of protein-bound glutamate $/ \mathrm{kg}$ ), as it reached $66.4 \pm 2 \mu \mathrm{mol}$ of glutamate $/ \mathrm{L}$ (1.6-fold over baseline) with a maximum at $45 \mathrm{~min}$. The same team studied the impact of a meal bringing $169 \mathrm{mg}$ of protein-bound glutamate/kg bw: plasma glutamate concentration increased significantly rising to $92.3 \pm 3$ $\mu \mathrm{mol} / \mathrm{L}$ (2.3-fold over baseline) at 120-150 min [49].

Compared to the meal used in the Tsai and Huang [41] study, which reflected ordinary Taiwanese dietary pattern, the one used by Stegink et al. [49], bringing $169 \mathrm{mg} /$ $\mathrm{kg}$ bw of protein-bound glutamate, was very unbalanced: hamburger $/ \mathrm{bun} / \mathrm{milk} /$ ice cream, providing $11 \mathrm{kcal} / \mathrm{kg}$, with $37 \%$ of the energy as protein $(1 \mathrm{~g} / \mathrm{kg}), 22 \%$ as carbohydrates, and $41 \%$ as fats. In conclusion, following an ordinary meal or an unbalanced one (37\% of the energy as proteins), plasma glutamate increase is between 1.5- and 2.3 -fold over baseline $(60-130 \mu \mathrm{mol} / \mathrm{L})$, thus remaining 5-10 times lesser than after ingestion of the same amount of glutamate alone under free form (MSG).

\section{Impact of Meals on Glutamate Pharmacokinetics following MSG Additive Ingestion}

The ten healthy men of Tsai [41] study were submitted to a second test day, 1 week after the first one. They were asked to eat the same meal with MSG $(100 \mathrm{mg} / \mathrm{kg}$ bw/day: 15,40 , and $45 \mathrm{mg} / \mathrm{kg}$ in breakfast, lunch, and dinner meals, respectively). Plasma glutamate increased significantly (1.4-fold over baseline, $53 \pm 21 \mu \mathrm{mol} / \mathrm{L}$ ) after each meal of MSG addition on the circadian profile of plasma glutamate levels.

Stegink et al. $[49,50]$ performed two studies to evaluate the impact of MSG additive on glutamate pharmacokinetics following meal ingestion (supplying $1 \mathrm{~g}$ of protein $/ \mathrm{kg}$ bw [169 mg glutamate $/ \mathrm{kg}$ ] and $10.8 \mathrm{kcal} / \mathrm{kg}$ [protein $26.9 \%$, fat $41 \%$, carbohydrate $22 \%$ ]) plus either 34 [49] or $150 \mathrm{mg} / \mathrm{kg}$ bw of MSG [50]. In the first one, total glutamate given to 12 healthy adults reached $196 \mathrm{mg} / \mathrm{kg}$ bw (i.e., supplied by MSG + protein). There was no difference in plasma glutamate following ingestion of the meal alone and ingestion of the meal plus $34 \mathrm{mg} / \mathrm{kg}$ bw of MSG (about $70 \mu \mathrm{mol} / \mathrm{L}$ ), and the mean areas under the plasma glutamate concentration time curve did not differ significantly [49]. The authors suggested that the quantity of protein-bound glutamate administered in this first 


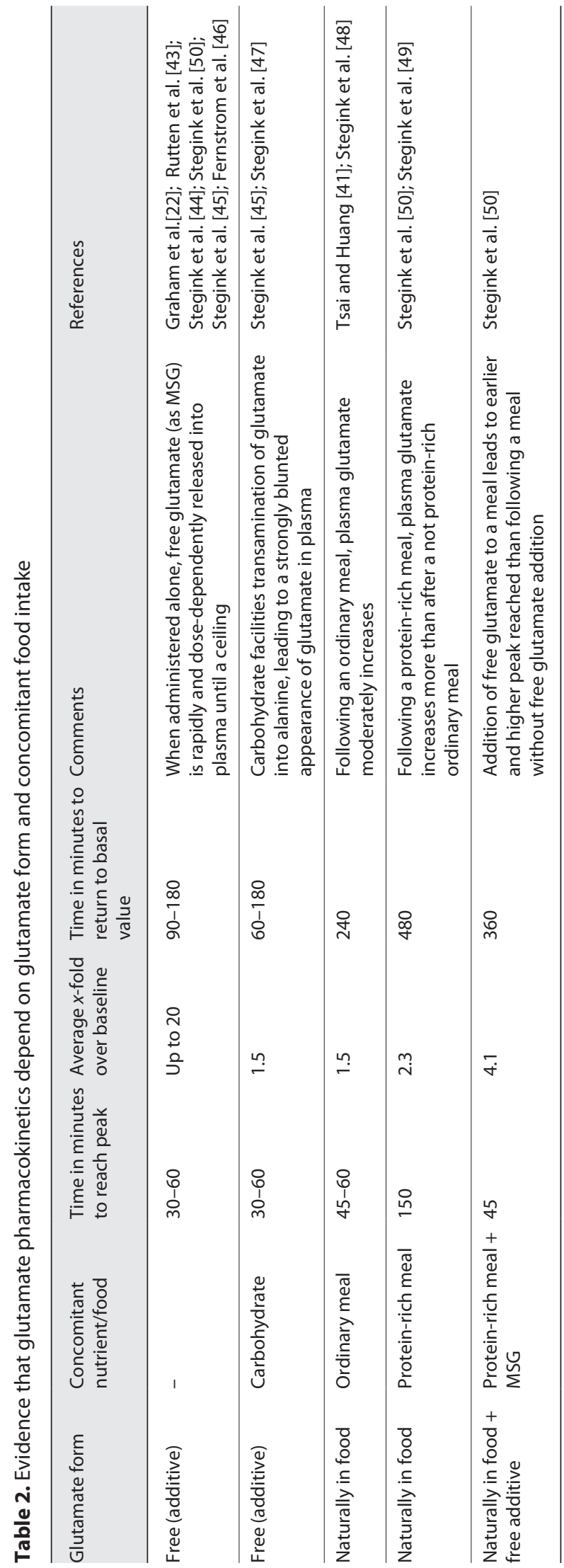

study was relatively large ( $169 \mathrm{mg} / \mathrm{kg} \mathrm{bw})$, and it was possible that the ingestion of this quantity of protein-bound glutamate obscured changes in plasma glutamate concentration arising from the free AA. This is why, in the second study, they added $150 \mathrm{mg} / \mathrm{kg}$ bw of MSG to the meal supplying $169 \mathrm{mg}$ of glutamate/kg bw, thus bringing a total of $286 \mathrm{mg}$ of glutamate $/ \mathrm{kg}$ bw to 6 healthy adults [50]. After the protein-rich meal alone, glutamate peaked at $120-150 \mathrm{~min}$ with values around 2.3 times the basal value $(129 \pm 35 \mu \mathrm{mol} / \mathrm{L})$. When glutamate was given with the protein-rich meal, the peak came earlier (i.e., $45 \mathrm{~min}$ ) with values 4.1 times the basal $(211 \pm 86 \mu \mathrm{mol} / \mathrm{L})$.

In conclusion, all these studies highlight that glutamate pharmacokinetics depend on concomitant food intake (Table 2). Addition of MSG to a meal leads to earlier and higher peak reach than when meal is consumed alone, but the plasma glutamate peak is blunted compared to the same MSG ingested alone. Nevertheless, per definition, an additive is added to a food and is not eaten alone. Therefore, only the latter studies, implying glutamate presented naturally in food or added to a food, make sense in the real life.

\section{Safety Data}

\section{Neuronal Safety}

As mentioned above, in the late 1960s, it was thought that consumption of glutamate induces increased brain glutamate levels, causing functional disruptions. Indeed, a subcutaneous injection of $1,000 \mathrm{mg} / \mathrm{kg}$ bw of MSG into newborn mice caused in 12-24 h neuronal destructions, leading to disturbed hypothalamic and pituitary functions [51]. When these animals grew to adulthood, they were found to be of below normal body length and obese, and had difficulty reproducing: the glutamate neurotoxicity hypothesis was born. Now, 50 years later, there are numerous data highlighting that ordinary human glutamate consumption is safe, and these data are detailed below.

Rodent studies failed to highlight dietary glutamate neurotoxicity. In its recent review, Fernstrom [52] reminds us that the threshold plasma glutamate concentration associated with the emergence of neurotoxicity in rodents in $3,580 \mu \mathrm{mol} / \mathrm{L}$. Whereas, while injection or rapid intubation of huge doses $(3,000-4,000 \mathrm{mg} / \mathrm{kg}$ bw) of free glutamate, as MSG, can rapidly elevate plasma glutamate concentrations to this threshold in rodents, when such extreme doses (up to $30,000 \mathrm{mg} / \mathrm{kg} \mathrm{bw}$ ) are ingested with freely available food or drinking water, plasma glu- 
tamate levels do not rise sufficiently to this threshold to cause neuronal lesions [53]. As examples, four works are of interest [54-57].

Anantharaman [54] conducted a 3-generation reproductive study in mice providing, in freely available drinking water, up to $6,000 \mathrm{mg}$ of glutamate $/ \mathrm{kg}$ bw for males, up to $7,200 \mathrm{mg}$ of glutamate/ $\mathrm{kg}$ bw for females and up to $25,000 \mathrm{mg}$ of glutamate $/ \mathrm{kg}$ bw for females during the 3 -week lactation. Exposure started during pregnancy. Results showed no alteration of growth, mortality, or reproduction in any generation, and no effect on neuronal aspects compared with controls [54].

Frieder and Grimm $[55,56]$ exposed Wistar rats to MSG in their freely available drinking water during the last 2 weeks of gestation so that $10,000 \mathrm{mg}$ of MSG/kg bw were ingested. Results indicated that compared to control rats, MSG rats presented a reduced birth weight, an increased bw at 28 days of life, a reduced activity in openfield and less rearing at 35 days of life, and they made more errors in a maze at 60 days of life. Using a similar protocol, the same authors highlighted that, compared to control rats, only male MSG rats presented an increase in hypothalamic and cortex choline uptake and choline acetyltransferase activity, and a reduction in hypothalamic and cortex norepinephrine uptake. The authors speculated that these changes could be "described as an inability to inhibit incorrect responses," but they also recognized a major limitation of this work, not having reproduced in 1987 [56] the results of the behavioural tests carried out in the first study in 1984 [55]. This failure makes an association highly speculative between behavioural changes observed in the first study [55] and neurochemical changes observed in the second study [56]. Furthermore, there are other limitations in these studies: no information was given on how pups were chosen for the tests or how data were analysed, and EFSA concluded that there were no effects when corrected for multiple testing.

Vorhees et al. [57] evaluated the developmental neurotoxicity of dietary exposure to free glutamate, as MSG, on somatic growth, landmark development, reflex ontogeny, neurobehavioural function, brain cell counts, and Golgi neuronal spine counts. They fed Sprague-Dawley rats with diets containing $1.7-5.1 \%$ of MSG prior to conception, throughout gestation and lactation, and to the offspring until 90 days of age. Results showed that rats ingested spontaneously from 1,300 to $8,200 \mathrm{mg}$ of glutamate/kg bw/day, according to the dosage and the period of life, with a lower consumption during gestation and higher during lactation. Among the 21 functional tests, dietary MSG administration had no effect on 17 of them.
Conversely, but only for the high dosage group (5.1\% of glutamate in the diet), dietary MSG administration produced delayed early swimming development, diminished rearing frequency in the open field, altered active avoidance acquisition and extinction, prolonged passive avoidance retention and tended to decrease running wheel activity. Authors concluded that the few behavioural deviations induced by dietary MSG must be regarded as minor from a safety standpoint since these effects appeared only with higher dosages and disappeared at lower doses [57].

Human studies show that dietary glutamate is neurosafe at very high doses. In the late 1960s, several case reports appeared in the scientific literature describing a complex of symptoms which came to be known as Chinese Restaurant Syndrome because they typically followed ingestion of a Chinese meal. Investigations have mainly focused on MSG as the causative agent in this syndrome, now called MSG symptom complex, characterized by headache, numbness/tingling, flushing, muscle tightness, and generalized weakness. This was supported by a study in which psychiatric patients received for 12 weeks daily doses of MSG up to 45,000 mg/day (about 600 $\mathrm{mg} / \mathrm{kg}$ bw/day for a $70 \mathrm{~kg}$ person, in three divided doses of $15,000 \mathrm{mg}$ [i.e., about $200 \mathrm{mg} / \mathrm{kg}$ at each dosing] diluted in tomato juice) $[58,59]$. Only minor side effects, typically nausea, have occasionally been reported at such high doses in these patients, without other physiological, psychological, biochemical, or behavioural effects [58]. In other studies where 5,000 mg of MSG was given included in meals (about $70 \mathrm{mg} / \mathrm{kg}$ bw/day for a $70 \mathrm{~kg}$ person), this MSG symptom complex has not been linked to the addition of MSG to food [60, 61]. Hence, there is no substantive evidence to demonstrate that symptoms associated with MSG symptom complex occur to any extent when glutamate is consumed as part of the diet [62]. By the way, glutamate has been administered in experiments, in most cases to adults as a single, oral dose up to $160 \mathrm{mg} / \mathrm{kg} \mathrm{bw}$ $[22,46,63]$, but also chronically, for up to 6 weeks at daily doses up to $150,000 \mathrm{mg} /$ day (about 2,000 mg/kg bw/day for a $70 \mathrm{~kg}$ person) without any deleterious effects: no clinical pathological changes, the only biochemically demonstrable effect was a decrease in serum cholesterol and associated beta lipoproteins [64].

However, as neuronal destructions have been observed in extreme conditions in rodents, brain investigations were performed following glutamate ingestion. Brain examination of included patients in clinical studies being unthinkable, a reliable and indirect measure of hypothalamus neuronal function through the measure of pituitary hormone secretion were obtained. Indeed, if a 
high oral dose of MSG causes the release of pituitary hormones, it would suggest that the plasma glutamate level has reached a level sufficient to penetrate the arcuate nucleus (a brain area of the hypothalamus, altered by high glutamate injection in mice [51]) and stimulate arcuate neurons that control pituitary hormone secretion. Fernstrom et al. [46] conducted such an experiment and showed that the plasma glutamate rise of 11 times the basal value $(530 \mu \mathrm{mol} / \mathrm{L})$ in 8 healthy adult subjects in the post-absorptive state consecutive to an administration of $160 \mathrm{mg}$ of MSG/kg bw was neither associated to an increase in plasma prolactin levels nor in levels of other pituitary hormones. This indicates that even a plasma glutamate rise of 11-fold over baseline is not sufficient to cause neuronal lesions. Knowing that even after a protein-rich meal supplemented with $160 \mathrm{mg}$ of free glutamate $/ \mathrm{kg}$ bw, plasma glutamate increases only 4.1 times the basal values $(211 \pm 86 \mu \mathrm{mol} / \mathrm{L})$ [50] (see above), it can be asserted that the extent to which plasma glutamate concentrations must rise to alter the brain is never encountered in humans consuming glutamate in their daily diet.

\section{Cardiovascular Safety}

Four recent epidemiological studies evaluated the effects of glutamate intake on cardiovascular parameters: blood pressure, hypertension, stroke, and cardiovascular mortality. The first one is a part of the important INTERMAP survey aimed to study diet-blood pressure relations in 4,680 persons (men and women aged 40-59 years) from 17 diverse population samples (diverse in geographic, socioeconomic, and ethnic composition) in four countries: China, Japan, USA, and UK [32, 65]. Since this survey previously highlighted an independent inverse relationship between dietary vegetable protein and the blood pressure of individuals, authors assessed whether blood pressure is associated with glutamate intake, an important dietary AA, especially in vegetable proteins. Each participant attended four times, visits 1 and 2 on consecutive days, visits 3 and 4 on consecutive days on average 3 weeks later. Each day, blood pressure was measured, all foods, drinks, supplements consumed in the previous 24 $\mathrm{h}$ were recorded, as well as MSG intake for China and USA participants (for Japan and UK participants MSG use was negligible and was not quantitated). Measurements of height, weight, and data on daily alcohol consumption over the previous 7 days were obtained at two visits and sodium, potassium, creatinine, and urea nitrogen were measured on 24-h urine collections. In addition, questionnaire data were obtained on demographic, bio- medical, and other possible confounders. Multivariate regression models were performed and controlled for age, gender, and sample, for the simplest model, and controlled for 16 non-nutrient (among which cardiovascular disease diagnostic, physical activity, family history of high blood pressure, cholesterol, urinary parameters...) and nutrient possible confounders for the most complex. Results showed that, after such adjustment for dietary and lifestyle factors, dietary glutamates (evaluated as a per cent of total protein intake and ranging from $17.8 \%$ of protein in Japan to $24.1 \%$ of protein in China, with an average for all participants of $15.7 \mathrm{~g} /$ day of total glutamate intake) was inversely related to blood pressure [32]: a 2 -SD higher intake of glutamates (4.7\% of total protein) was associated with a $1.5 \mathrm{~mm} \mathrm{Hg}$ lower systolic blood pressure and $1.0 \mathrm{~mm} \mathrm{Hg}$ lower diastolic blood pressure.

The purpose of the second clinical study was to examine whether the intake of glutamates was associated with blood pressure levels $(n=3,086)$ and incident hypertension $(n=1,810)$ in the Rotterdam Study [34]. The Rotterdam Study evaluated the occurrence and progression of chronic diseases and their risk factors in people aged more than 55 years and included residents of a suburb of Rotterdam. Blood pressure levels were calculated in quartiles of AA intake as a percentage of total protein intake with adjustment for age, sex, BMI, smoking, alcohol intake, education, and dietary factors. Then, the associations between specific AA intake and hypertension incidence were studied by multivariate regression models. The authors could not confirm the inverse association highlighted in the INTERMAP Study between glutamate intake (with an average for all participants of $17 \mathrm{~g} /$ day of total glutamates intake) and blood pressure [32]. In addition, incidence of hypertension was not influenced by ingested glutamate. They explained this fail by the possible excessive homogeneity of glutamate consumption in their Rotterdam Study cohort. Indeed, the INTERMAP Study included participants from four different countries with larger variations in glutamate intake (one standard deviation $=2.4 \%$ of protein) in comparison with the Rotterdam Study cohort (one standard deviation $=1.1 \%$ of protein) [34].

In the third study, the authors were interested in the association between glutamates (and glycine) intake and the risk of mortality from stroke in the cohort of Takayama Study [35]. This study was held in Takayama City, Gifu, Japan, when residents, aged more than 35 years, provided information on their lifestyle and medical history. It is an ongoing prospective cohort study to investigate associations between diet and other lifestyle factors 
with cancer and other chronic diseases. Authors excluded subjects who reported having or having had cancer and stroke or coronary heart disease on the baseline questionnaire. In total, 29,079 subjects $(13,355$ men and 15,724 women) were included in these analyses. Their diets were assessed by a validated food frequency questionnaire at baseline. Deaths from stroke (haemorrhage, ischemic and undetermined type of stroke) were ascertained over 16 years. The association between glutamates intake (expressed as a percentage of total protein intake) and death from stroke were studied by multivariate regression models with adjustment for age, total energy intake, non-dietary factors (marital status, level of education, height, BMI, smoking status, physical activity, alcohol consumption, histories of diabetes and hypertension, menopausal status), and dietary factors (intake of total protein, saturated fat, polyunsaturated fat, salt, and dietary fibre). Results showed that, in men, glutamates intake was not significantly associated with risk of mortality from total stroke after controlling for covariates whereas in women, the highest quartile of glutamates intake was significantly associated with a decreased risk of total stroke mortality since the hazard ratio per $1 \%$ increase in glutamates intake was 0.84 . In addition, there was no significant association between animal or vegetable protein and the risk of mortality from total or any subtype of stroke in both men and women. Nevertheless, these results must be confirmed in cohorts in which food consumption analysis is performed periodically throughout the study, not just at baseline in the Takayama study.

Lastly, Ma et al. [36] prospectively examined dietary intakes of the most abundant AAs in the human body, namely glutamine and its product, glutamate, and their ratio. They studied their relation to total and cause specific mortality in 74,082 women registered nurses aged 30-55 years from 11 US states (from the Nurses' Health Study [1984-2012]) and in 42,303 male health professionals aged 40-75 years from all 50 US states (from the Health Professionals Follow-up Study [1986-2012]). Individuals with cancer or cardiovascular disease (coronary heart disease, stroke, angina, and coronary artery bypass grafting) at baseline or those who had incomplete or inconsistent information for dietary data were excluded. Participants were followed with the use of biennial validated questionnaires concerning medical history, lifestyle, including validated semi-quantitative food frequency questionnaires, and health practices. Deaths and underlying cause of death were recorded, considering deaths due to cardiovascular disease and those due to cancer. Participants were divided into quintiles according to

Glutamate: A Safe Nutrient, Not Just a Simple Additive their energy-adjusted intake of glutamine, glutamate, and glutamine-to-glutamate ratio. Multivariate analysis was performed with adjustment for potential confounders including age, demographics, lifestyle, and dietary factors. When considering only age as a covariate, pooled extreme quintile was associated with higher risk of mortality (all cause), but this association was no longer statistically significant when other confounders were taken into account. By the way, multivariate analysis with adjustment for age, demographics, lifestyle and dietary factors showed that higher intake of glutamate (8 $\mathrm{g} /$ day of food glutamate in the highest quintile for women and $9.6 \mathrm{~g} /$ day for men) was associated with a trend to a higher risk of cardiovascular mortality (pooled extreme quintile hazard ratio: 1.09 ; $95 \%$ CI: $1.00,1.17 ; p=0.03)$, but this trend was no longer apparent when considering higher intake of glutamine-to-glutamate ratio which was inversely related to cardiovascular mortality (pooled extreme quintile hazard ratio: $0.81 ; 95 \% \mathrm{CI}: 0.75,0.88 ; p<0.001$, respectively). In addition, glutamate intake was not associated with cancer mortality. Moreover, higher intake of glutamine and higher glutamine-to-glutamate ratio were significantly associated with lower risk of total mortality (pooled extreme quintile hazard ratio: 0.85 ; 95\% CI: $0.82,0.89 ; p<$ 0.001 and $0.87 ; 95 \%$ CI: $0.84,0.91 ; p<0.001$, respectively) and lower risk of cancer mortality (pooled extreme quintile hazard ratio: $0.89 ; 95 \% \mathrm{CI}: 0.83,0.95 ; p<0.001$ and $0.93 ; 95 \%$ CI: $0.87,0.99 ; p<0.001$, respectively). Together these results indicate that when considering confounders including age, demographics, lifestyle, and dietary factors and considering that glutamate is ingested during a meal, as usual, i.e., in the presence of glutamine, higher glutamine-to-glutamate ratio were significantly associated with lower risk of mortality (all causes), cardiovascular mortality and cancer mortality.

\section{Nutritional Safety}

A first epidemiological study was published in 2008 by He et al. [66] who examined the association between MSG intake (i.e., just the additive intake, not total glutamates consumption) and overweight $\left(23 \leq \mathrm{BMI} \leq 25 \mathrm{~kg} / \mathrm{m}^{2}\right)$ in 752 healthy Chinese from rural area, participants of the INTERMAP cohort [65]. MSG non-users (17.6\%) served as reference group; MSG users were divided into tertiles according to MSG intake. Odds ratios of overweight were calculated by comparing each MSG intake group to nonusers. With adjustments for potential confounders including physical activity and total energy intake, MSG intake (median of $0.08,0.28$ and $0.70 \mathrm{~g} /$ day for tertiles $\mathrm{T} 1$, $\mathrm{T} 2$, and $\mathrm{T} 3$, respectively) was positively related to body 
mass index (extreme tertile odds ratio: $2.75 ; 95 \%$ CI: 1.28 , 5.05; $p=0.04)$. But this study has one major limitation: total fat intake, also expressed as a per cent of energy intake, increased (non-users: 17.2\%, T1: 18.8\%, T2: $20.4 \%$ and T3: $22.4 \%, p<0.01$ ), together with energy (non-users: 1,965 kcal, T1: 1,951 kcal, T2: 2,031 and T3: 2,216 kcal, $p$ $<0.01)$. Thus, it is not excluded that there is an interpretation bias in the study of $\mathrm{He}$ et al. [66] as suggested by Shi et al. [33]. It would be of interest to repeat the analysis with adjustment for fat intakes.

The same author analysed data collected from a representative sample of the Chinese population: the China Health and Nutrition Survey [67]. He et al. [67] study included 10,095 adults divided into quintiles according to their MSG consumption and followed on average for 5 years. A relation between MSG consumption and BMI increase was highlighted by the multivariate analysis adjusted for age, sex, urban residence, and region (south or north area), smoking status, alcohol consumption, education, physical activity, and dietary intakes of total energy, sodium, potassium, and calcium. Interestingly, authors suggested an association between MSG consumption and serum leptin concentrations. Nevertheless, only participants in the highest quintile, with a MSG mean consumption of $4.19 \mathrm{~g} /$ day (which is almost double of the highest adult consumption in the Tennant review [Table 1]), presented an increased hazard ratios of overweight (hazard ratio: Q1: 1.00, Q2: 1.00 [95\% CI: 0.75, 1.32]; Q3: 0.83 [95\% CI: 0.63, 1.10]; Q4: 0.96 [95\% CI: $0.73,1.27$ ]; Q5: 1.33 [95\% CI: 1.01, 1.75]; $p<0.01$ ). Again, one major limitation of this study is the fact that fat consumptions increased according quintiles and this confounding factor has not been taken into account. In addition, and as written by He himself, their "ability to examine the relation of MSG intake with obesity was limited by the relatively small number of participants with BMI $\geq 30$."

Results of these two previous He et al. $[66,67]$ studies are supported by a small Thai one aimed to determine whether MSG is associated with the metabolic syndrome [68]. For this purpose, data were collected from 349 adults living in a rural area of Thailand, who were provided with $250 \mathrm{~g}$ of MSG in a plastic box to be used as the sole source of MSG for food preparation for 10 days. Participants were divided into tertiles according to their MSG consumption (median MSG intake in grams per day [interquartile range]: T1: 1.9 [1.5-2.3]; T2:3.6 [3.2-4.2]; T3: 6.0 [5.2-7.4]). There were no differences of energy, fat, carbohydrate or protein intake among tertiles. Results showed an increasing prevalence of overweight ( $p=$
$0.021)$ and metabolic syndrome $(p=0.014)$ across the different tertiles and binary logistic regression analysis adjusting for sex, age, family history of diabetes mellitus, smoking status, physical activity levels, and total energy intake highlighted an independent association between MSG consumption and increased risk of overweight (odds ratio [95\% CI]: 1.16 [1.04-1.29], $p=0.007$ ) and metabolic syndrome (1.14 [1.12-1.28], $p=0.007)$ [68]. It is of interest to note that in this study, MSG consumption in T2 and T3 is much higher than the highest adult consumption in the Tennant review (Table 1).

On the other hand, Thu Hien et al. [69] failed to highlight an association between MSG consumption and overweight. They evaluated dietary intake by the 24 $\mathrm{h}$ recall method for 3 days of 1,528 adults living either in urban or in rural area in north, central, or south Vietnam and usually taking their meals at home. They also collected data on age, sex, region of residence and ethnic background, education, occupation, physical activities, lifestyle factors, and medical history. The prevalence of overweight was $27.9 \%$, and $81.0 \%$ of participants were MSG users. Average MSG intake was 2.2 $( \pm 1.8) \mathrm{g} /$ day. Multiple logistic regression analysis adjusted for educational levels and smoking status revealed that factors associated with overweight, defined as BMI $\geq 23 \mathrm{~kg} / \mathrm{m}^{2}$, were age, region of residence, lifelong occupation, physical activity and intakes of energy, carbohydrates, saturated fat and animal protein. There was no significant association between MSG intake, according to quartiles, and overweight (odds ratio [95\% CI]: non-users: 1.00; Q1: 1.15 [0.80-1.65]; Q2: 0.87 [0.56-1.35]; Q3: 0.69 [0.47-1.00]; Q4: 0.88 [0.63-1.22]; $p>0.05)$ [69].

From these four previous studies, it can be concluded that a relation exists between MSG consumption and BMI. But to increase risk of overweight or metabolic syndrome, MSG consumption should be higher than $3.8 \mathrm{~g} /$ day $[33,67,68]$, representing $54 \mathrm{mg} / \mathrm{kg}$ bw/day, which is much higher than the highest adult consumption in the Tennant review (Table 1). In other words, the main question should be: does MSG consumption lead to obesity or to clinically significant weight gain?

Answering the question was the aim of the study of Shi et al. [33]. For that purpose, 1,227 persons were included (a subsample of the Jiangsu Nutrition cohort), neither with diabetes, stroke, or cancer at baseline nor extreme weight change (i.e., $>20 \mathrm{~kg}$ ) over the previous 5 years. Participants were divided into quartiles according to MSG intake and into three groups according to weight change: weight loss (loss $\geq 5 \%$ ), weight maintenance (change 
$<5 \%$ ), and weight gain (gain $\geq 5 \%$ ). Multilevel mixed-effects linear regression was used to determine the association between MSG intake and weight change adjusted for age, education, occupation, active commuting, leisure time physical activity, smoking, alcohol drinking, eating out, and energy intake. Another confounder factor used was food pattern as four patterns were identified: high intake of animal foods and alcohol/traditional (loaded heavily on rice and fresh vegetables, and inversely on wheat starch)/high consumption of cake, milk, yoghurt, and drinks/vegetable-rich (whole grains, fruits, root vegetables, fresh and pickled vegetables, milk, eggs, and fish). These four patterns explained $28.5 \%$ of the variance in intake. In quartiles, MSG intake ranged from 2.5 to 9 times greater than the MSG intake of non-MSG consumers and no significant difference in energy and protein intake was found across MSG intake quartiles. Across quartiles of MSG intake, there was a significant decrease in the prevalence of obesity ( $p=0.016)$ but after adjusting for age, sex, lifestyle, energy intake and food patterns, MSG intake was not associated with a higher prevalence of obesity. In the same way, after adjusting for lifestyle, demographic factors, energy intake, sex and total glutamate intake, a linear inverse trend between MSG intake and $5 \%$ weight gain was observed (extreme quartile odds ratio: $0.47 ; 95 \%$ CI: $0.27,0.84 ; p=0.028$ ). However, this association disappeared with addition of adjustment for either rice intake (extreme quartile odds ratio: $0.93,95 \%$ CI: $0.54,1.60 ; p=0.90$ ) or food patterns (extreme quartile odds ratio: $0.94,95 \%$ CI: $0.54,1.63$; $p=0.85$ ). Thus, authors concluded that MSG intake is not associated with prevalence of obesity or with a clinically significant weight gain over 5 years and suggested that further research is warranted in individuals who have a poor protein and energy status.

In conclusion, the extent to which plasma glutamate concentration must rise to alter the brain is never encountered in humans consuming glutamate in their daily diets, whatever its origin (naturally in diet or additive), as glutamate is highly metabolized in the splanchnic area. Included in diet, glutamate does not present any adverse effects in man. Some studies demonstrated a trend to an inverse relationship between glutamates intake and blood pressure, risk of mortality and stroke mortality, and usual MSG consumption seems not to be associated with clinically significant weight gain. All these results have to be confirmed by larger prospective cohort studies or meta-analysis. In other words, glutamate consumption in ordinary diet is safe.

Glutamate: A Safe Nutrient, Not Just a Simple Additive

\section{Conclusion}

The EFSA considered the Vorhees et al. [57] study to establish a no-observed-adverse effect level (NOAEL) of $3,200 \mathrm{mg}$ of glutamate/kg bw/day. Applying a default uncertainty factor of 100 (consisting of 2 times a factor 10 to account for each interspecies variation and inter-individual variation) to this NOAEL of $3,200 \mathrm{mg} / \mathrm{kg}$ bw/day, the EFSA defined an ADI of $30 \mathrm{mg}$ of free additive glutamate/ $\mathrm{kg}$ bw/day [4]. However, Vorhees himself disagrees with this ADI value and to claim objectively his disagreement, in 2018, he re-evaluated his own work [70]. In particular, he contextualized the study: in 1979, there were no guidelines on how developmental neurotoxicity experiments should be done and today, most tests are no longer used because of lack of sensitivity or prediction of long-term neurotoxicity. Therefore, he questioned the reliability of his previous study, arguing also that this study has never been used by regulatory authorities worldwide for the safety assessment of glutamate despite it being available for nearly 40 years. He concluded, as he and the US Food and Drug Administration did in 1979, that there is no evidence in these data that dietary glutamate is developmentally neurotoxic and that the study provides no basis for the establishment of a NOAEL and changing the ADI for dietary glutamate [70]. In addition, such an ADI of 30 $\mathrm{mg}$ of free additive glutamate $/ \mathrm{kg} \mathrm{bw} /$ day is at a level below the normal dietary free glutamate intake for toddlers and children (even in breastfed infants), as mentioned above in Table 1. On the basis of glutamate literature, and particularly on toxicokinetic data, Roberts et al. [62] proposed to reduce the uncertainty factor for interspecies differences between rat and man from 10 to 2.5 given that the toxicokinetics of glutamate, when given as a bolus dose or administered as part of the diet, is similar in both species. In addition, instead of defining a NOAEL from the Vorhees study [57], they suggested to define it from the 3-generation reproductive study in mice of Anantharaman [54]. In this study, it was highlighted that 6,000 $\mathrm{mg}$ of glutamate $/ \mathrm{kg}$ bw/day failed to impact growth, mortality, reproductive, or brain histopathology. Thus, use of an uncertainty factor of 25 and a NOAEL of $6,000 \mathrm{mg}$ of glutamate $/ \mathrm{kg} \mathrm{bw} /$ day lead to an ADI of at least $240 \mathrm{mg} / \mathrm{kg}$ bw/day [62]. But four points should be considered. Firstly, there is a lack of deleterious effects of bolus or chronic high dose (up to $150 \mathrm{~g}$ ) of glutamate [60-62, 64]. Secondly, intake of dietary glutamates could be far below $240 \mathrm{mg} /$ $\mathrm{kg}$ bw/day particularly in toddlers and children [31]. Thirdly, glutamate taste (umami) is self-limiting [18]. And fourthly, a practical limit on glutamate use in final

Ann Nutr Metab 2022;78:133-146 
foods already exists ( $10 \mathrm{~g} / \mathrm{kg}$ of food) in the EU. Thus, it can be concluded that there is no compelling evidence to indicate that the previous ADI of "not specified" warrants any change, especially since glutamate is a nutrient and not just an additive. In the same way, regulatory authorities worldwide came to the conclusion that glutamate poses no safety concerns at levels of current dietary consumption [62].

The 2021 EFSA Statement suggests to establish tolerable upper intake levels (ULs) for nutrients [6]. These ULs are expressed as milligrams or micrograms of a given nutrient per day for defined population groups (e.g., infants, children, adolescents, adults, pregnant women, lactating women). They represent the maximum level of total chronic daily intake of a nutrient (from all sources) judged to be unlikely to pose a risk of adverse health effects to humans. To establish such ULs, experts should refer to data on glutamate intake in food and drinks by infants, toddlers, children, adolescents, adults, and elderly published by Tennant [31] and summarized in Table 1 .

\section{Acknowledgments}

The authors would like to thank Dr. David Tennant for his permission to reproduce the data contained in Table 1.

\section{Conflict of Interest Statement}

The authors declare no conflict of interest. The funders had no role in the design of the study; in the collection, analyses, or interpretation of data; in the writing of the manuscript; or in the decision to publish the results.

\section{Funding Sources}

This work was supported by a grant from the International Glutamate Technical Committee (IGTC), Brussels, Belgium.

\section{Author Contributions}

C.L. wrote the core of the first draft. L.C. contributed to write and improve the manuscript. All authors have read and agreed to the published version of the manuscript.

\section{References}

1 Beyreuther K, Biesalski HK, Fernstrom JD, Grimm P, Hammes WP, Heinemann U, et al. Consensus meeting: monosodium glutamate - an update. Eur J Clin Nutr. 2007;61(3):30413.

2 Joint FAO/WHO Expert Committee on Food Additives (JECFA). Evaluation of certain food additives and contaminants. Thirty-first report of the Joint FAO/WHO expert committee on food additives. WHO technical report series; 1987. Vol. 759. Available from: http:// whqlibdoc.who.int/trs/WHO_TRS_759.pdf.

3 Scientific Committee for Food (SCF). First series of food additives of various technological functions. Opinion expressed on 18 May 1990. Reports of the Scientific Committee for Food, 25th series. 1991.

4 EFSA Panel on Food Additives and Nutrient Sources added to Food (ANS); Mortensen A, Aguilar F, Crebelli R, Dusemund B, Frutos M, et al. Re-evaluation of glutamic acid (E 620), sodium glutamate (E 621), potassium glutamate (E 622), calcium glutamate (E 623), ammonium glutamate (E 624) and magnesium glutamate (E 625) as food additives. EFSA J. 2017;15:4910.

5 Cynober L, Fernstrom JD, Koletzko B, Rietjens IMCM, Roberts A, Tennant DR, et al. Introduction and summary of the $2018 \mathrm{di}$ etary glutamate workshop. Ann Nutr Metab. 2018;73(Suppl 5):1-4.
6 Scientific Committee EFSA; More S, Bampidis V, Benford D, Bragard C, Halldorsson T, et al. Statement on the derivation of healthbased guidance values (HBGVs) for regulated products that are also nutrients. EFSA J. 2021; 19:e06479.

7 Zhang Y, Venkitasamy C, Pan Z, Liu W, Zhao L. Novel umami ingredients: umami peptides and their taste. J Food Sci. 2017;82(1):16-23.

8 Cynober L. Metabolism of dietary glutamate in adults. Ann Nutr Metab. 2018;73(Suppl 5): 5-14.

9 Battezzati A, Brillon DJ, Matthews DE. Oxidation of glutamic acid by the splanchnic bed in humans. Am J Physiol. 1995;269(2 Pt 1): E269-76.

10 Matthews DE, Marano MA, Campbell RG. Splanchnic bed utilization of glutamine and glutamic acid in humans. Am J Physiol. 1993; 264(6 Pt 1):E848-54.

11 Rutten EP, Engelen MP, Castro CL, Wouters EF, Schols AM, Deutz NE. Decreased wholebody and splanchnic glutamate metabolism in healthy elderly men and patients with chronic obstructive pulmonary disease in the postabsorptive state and in response to feeding. J Nutr. 2005;135(9):2166-70.

12 Tomé $\mathrm{D}$. The roles of dietary glutamate in the intestine. Ann Nutr Metab. 2018;73(Suppl 5): 15-20.

13 Watford M. Glutamine and glutamate metabolism across the liver sinusoid. J Nutr. 2000; 130(4S Suppl):983S-7S.
14 Rémésy C, Moundras C, Morand C, Demigné C. Glutamine or glutamate release by the liver constitutes a major mechanism for nitrogen salvage. Am J Physiol. 1997;272(2 Pt 1):G25764.

15 Stoll B, McNelly S, Buscher HP, Haussinger D. Functional hepatocyte heterogeneity in glutamate, aspartate and alpha- ketoglutarate uptake: a histoautoradiographical study. Hepatology. 1991;13(2):247-53.

16 Moundras C, Rémésy C, Bercovici D, Demigné C. Effect of dietary supplementation with glutamic acid or glutamine on the splanchnic and muscle metabolism of glucogenic amino acids in the rat. J Nutr Biochem. 1993;4(4): 222-8.

17 Kowalski TJ, Watford M. Production of glutamine and utilization of glutamate by rat subcutaneous adipose tissue in vivo. Am J Physiol. 1994;266(1 Pt 1):E151-4.

18 Yamaguchi S, Takahashi C. Hedonic functions of monosodium glutamate and four basic taste substances used at various concentration levels in single and complex systems. Agric Biol Chem. 1984;48(4):1077-81.

19 Darmaun D, Matthews DE, Bier DM. Glutamine and glutamate kinetics in humans. Am J Physiol. 1986;251(1 Pt 1):E117-26.

20 Marliss EB, Aoki TT, Pozefsky T, Most AS, Cahill GF. Muscle and splanchnic glutmine and glutamate metabolism in postabsorptive andstarved man. J Clin Invest. 1971;50(4): 814-7. 
21 Deutz NE. The 2007 ESPEN Sir David Cuthbertson Lecture: amino acids between and within organs. The glutamate-glutamine-citrulline-arginine pathway. Clin Nutr. 2008; 27(3):321-7.

22 Graham TE, Sgro V, Friars D, Gibala MJ. Glutamate ingestion: the plasma and muscle free amino acid pools of resting humans. Am J Physiol Endocrinol Metab. 2000;278(1):E83-

23 Darmaun D, Matthews DE, Desjeux JF, Bier DM. Glutamine and glutamate nitrogen exchangeable pools in cultured fibroblasts: a stable isotope study. J Cell Physiol. 1988; 134(1):143-8.

24 Chambon-Savanovitch C, Farges MC, Raul F, Blachier F, Davot P, Cynober L, et al. Can a glutamate-enriched diet counteract glutamine depletion in endotoxemic rats? J Nutr Biochem. 1999;10(6):331-7.

25 Brosnan JT. Glutamate, at the interface between amino acid and carbohydrate metabolism. J Nutr. 2000;130(4S Suppl):988S-90S.

26 Young VR, Ajami AM. Glutamate: an amino acid of particular distinction. J Nutr. 2000; 130(4S Suppl):892S-900S.

27 Maher TJ, Glaeser BS, Wurtman RJ. Diurnal variations in plasma concentrations of basic and neutral amino acids and in red cell concentrations of aspartate and glutamate: effects of dietary protein intake. Am J Clin Nutr. 1984;39(5):722-9.

28 Darmaun D, Robert J, Bier D, Matthews D, Young V. Etude in vivo du métabolisme des acides aminés non essentiels par les isotopes stables: application à l'alanine, à la glutamine et au glutamate. Ann Endocrinol. 1985;46: 355-6.

29 Rangan C, Barceloux DG. Food additives and sensitivities. Dis Mon. 2009;55(5):292-311.

30 Dillon J. L'acide glutamique. Cah Nutr Diét. 1991;26:157-62.

31 Tennant DR. Review of glutamate intake from both food additive and non-additive sources in the European Union. Ann Nutr Metab. 2018;73(Suppl 5):21-8.

32 Stamler J, Brown IJ, Daviglus ML, Chan Q, Kesteloot H, Ueshima H, et al. Glutamic acid, the main dietary amino acid, and blood pressure: the INTERMAP Study (International Collaborative Study of Macronutrients, Micronutrients and Blood Pressure). Circulation. 2009;120(3):221-8.

33 Shi Z, Luscombe-Marsh ND, Wittert GA, Yuan B, Dai Y, Pan X, et al. Monosodium glutamate is not associated with obesity or a greater prevalence of weight gain over 5 years: findings from the Jiangsu Nutrition Study of Chinese adults. Br J Nutr. 2010;104(3):45763.

34 Altorf-van der Kuil W, Engberink MF, De Neve M, van Rooij FJA, Hofman A, van't Veer $\mathrm{P}$, et al. Dietary amino acids and the risk of hypertension in a Dutch older population: the Rotterdam Study. Am J Clin Nutr. 2013;97(2): 403-10.
35 Nagata C, Wada K, Tamura T, Kawachi T, Konishi K, Tsuji M, et al. Dietary intakes of glutamic acid and glycine are associated with stroke mortality in Japanese adults. J Nutr. 2015;145(4):720-8.

36 Ma W, Heianza Y, Huang T, Wang T, Sun D, Zheng $Y$, et al. Dietary glutamine, glutamate and mortality: two large prospective studies in US men and women. Int J Epidemiol. 2018; 47(1):311-20.

37 Brosnan JT, Drewnowski A, Friedman MI. Is there a relationship between dietary MSG and [corrected] obesity in animals or humans? Amino Acids. 2014;46(9):2075-87.

38 Rhodes J, Titherley AC, Norman JA, Wood R, Lord DW. A survey of the monosodium glutamate content of foods and an estimation of the dietary intake of monosodium glutamate. Food Addit Contam. 1991;8(5):663-72.

39 Giacometti T. Free and bound glutamate in natural products. In: Filer LJ Jr, Garattini S, Kare MR, Reynolds WA, Wurtman RJ, editors. Glutamic acid: advances in biochemistry and physiology. New York: Raven Press; 1979. p. 25-34.

40 Maga JA. Flavor potentiators. Crit Rev Food Sci Nutr. 1983;18(3):231-312.

41 Tsai PJ, Huang PC. Circadian variations in plasma and erythrocyte concentrations of glutamate, glutamine, and alanine in men on a diet without and with added monosodium glutamate. Metabolism. 1999;48(11):145560.

42 Eriksson T, Voog L, Wålinder J, Eriksson TE. Diurnal rhythm in absolute and relative concentrations of large neutral amino acids in human plasma. J Psychiatr Res. 1989;23(3-4): 241-9.

43 Rutten EP, Engelen MP, Wouters EF, Schols AM, Deutz NE. Metabolic effects of glutamine and glutamate ingestion in healthy subjects and in persons with chronic obstructive pulmonary disease. Am J Clin Nutr. 2006; 83(1):115-23.

44 Stegink LD, Filer LJ, Baker GL. Plasma glutamate concentrations in adult subjects ingesting monosodium L-glutamate in consomme. Am J Clin Nutr. 1985;42(2):220-5.

45 Stegink LD, Filer LJ, Baker GL. Effect of carbohydrate on plasma and erythrocyte glutamate levels in humans ingesting large doses of monosodium L-glutamate in water. Am J Clin Nutr. 1983;37(6):961-8.

46 Fernstrom JD, Cameron JL, Fernstrom MH, McConaha C, Weltzin TE, Kaye WH. Shortterm neuroendocrine effects of a large oral dose of monosodium glutamate in fasting male subjects. J Clin Endocrinol Metab. 1996; 81(1):184-91.

47 Stegink LD, Filer LJ, Baker GL, Bell EF. Effect of sucrose ingestion on plasma glutamate concentrations in humans administered monosodium L-glutamate. Am J Clin Nutr. 1986;43(4):510-5.
48 Stegink LD, Baker GL, Filer LJ. Modulating effect of Sustagen on plasma glutamate concentration in humans ingesting monosodium L-glutamate. Am J Clin Nutr. 1983;37(2): 194-200.

49 Stegink LD, Filer LJ, Baker GL. Plasma and erythrocyte amino acid levels in normal adult subjects fed a high protein meal with and without added monosodium glutamate. J Nutr. 1982;112(10):1953-60.

50 Stegink LD, Filer LJ, Baker GL. Plasma amino acid concentrations in normal adults fed meals with added monosodium L-glutamate and aspartame. J Nutr. 1983;113(9):1851-60.

51 Olney JW. Brain lesions, obesity, and other disturbances in mice treated with monosodium glutamate. Science. 1969;164(3880):71921.

52 Fernstrom JD. Monosodium glutamate in the diet does not raise brain glutamate concentrations or disrupt brain functions. Ann Nutr Metab. 2018;73(Suppl 5):43-52.

53 Takasaki Y, Matsuzawa Y, Iwata S, O'Hara Y, Yonetani S, Ichimura M. Toxicological studies of monosodium L-glutamate in rodents: relationship between routes of administration and neurotoxicity. In: Filer LJ Jr, Garattini S, Kare MR, Reynolds WA, Wurtman RJ, editors. Glutamic acid: advances in biochemistry and physiology. 1979. p. 255-75.

54 Anantharaman K. In utero and dietary administration of monosodium L-glutamate to mice: reproductive performance and development in a multigeneration study. In: Filer LJ Jr, Garattini S, Kare MR, Reynolds WA, editors. Glutamic acid: advances in biochemistry and physiology. New York: Raven Press; 1979. p. 231-53.

55 Frieder B, Grimm VE. Prenatal monosodium glutamate (MSG) treatment given through the mother's diet causes behavioral deficits in rat offspring. Int J Neurosci. 1984;23(2):11726.

56 Frieder B, Grimm VE. Prenatal monosodium glutamate causes long-lasting cholinergic and adrenergic changes in various brain regions. J Neurochem. 1987;48(5):1359-65.

57 Vorhees CV, Butcher RE, Brunner RL, Sobotka TJ. A developmental test battery for neurobehavioral toxicity in rats: a preliminary analysis using monosodium glutamate calcium carrageenan, and hydroxyurea. Toxicol Appl Pharmacol. 1979;50(2):267-82.

58 Himwich HE, Wolff K, Hunsicker AL, Himwich WA. Some behavioral effects associated with feeding sodium glutamate to patients with psychiatric disorders. J Nerv Ment Dis. 1955;121(1):40-9.

59 Himwich WA, Petersen IM. Ingested sodium glutamate and plasma levels of glutamic acid. J Appl Physiol. 1954;7(2):196-9.

60 Kenney RA. Effect of concurrent caloric intake on the response to oral monosodium Lglutamate in susceptible subjects. J Food Sci. 1974;39(2):414-5. 
61 Geha RS, Beiser A, Ren C, Patterson R, Greenberger PA, Grammer LC, et al. Multicenter, double-blind, placebo-controlled, multiplechallenge evaluation of reported reactions to monosodium glutamate. J Allergy Clin Immunol. 2000;106(5):973-80.

62 Roberts A, Lynch B, Rietjens IMCM. Risk assessment paradigm for glutamate. Ann Nutr Metab. 2018;73(Suppl 5):53-64.

63 Stegink L, Reynolds W, Filer L, Baker G, Daabees T, Pitkin R. Comparative metabolism of glutamate in the mouse, monkey and man. In: Filer LJ, Garattini S, Kare MR, Reynolds WA, Wurtman RJ, editors. Glutamic acid: advances in biochemistry and physiology. New York: Raven Press; 1979. p. 85-102.
64 Bazzano G, D’Elia JA, Olson RE. Monosodium glutamate: feeding of large amounts in man and gerbils. Science. 1970;169(3951): $1208-9$.

65 Stamler J, Elliott P, Dennis B, Dyer A, Kesteloot $\mathrm{H}$, Liu $\mathrm{K}$, et al. INTERMAP: background, aims, design, methods, and descriptive statistics (nondietary). J Hum Hypertens. 2003;17(9):591-608.

66 He K, Zhao L, Daviglus ML, Dyer AR, Van Horn L, Garside D, et al. Association of monosodium glutamate intake with overweight in Chinese adults: the INTERMAP Study. Obes Silver Spring Md. 2008;16(8):1875-80.

67 He K, Du S, Xun P, Sharma S, Wang H, Zhai F, et al. Consumption of monosodium glutamate in relation to incidence of overweight in Chinese adults: China Health and Nutrition Survey (CHNS). Am J Clin Nutr. 2011;93(6):1328-36.
68 Insawang T, Selmi C, Cha'on U, Pethlert S, Yongvanit $\mathrm{P}$, Areejitranusorn $\mathrm{P}$, et al. Monosodium glutamate (MSG) intake is associated with the prevalence of metabolic syndrome in a rural Thai population. Nutr Metab. 2012; 9(1):50.

69 Thu Hien VT, Thi Lam N, Cong Khan N, Wakita A, Yamamoto S. Monosodium glutamate is not associated with overweight in Vietnamese adults. Public Health Nutr. 2013. 16(5):922-7.

70 Vorhees CV. A test of dietary monosodium glutamate developmental neurotoxicity in rats: a reappraisal. Ann Nutr Metab. 2018;73 Suppl 5:36-42. 